\title{
The Effect of Peer Instruction on Promoting Student Nurses' Learning in Medical-Surgical Nursing
}

\author{
Mei Ki Cheung \\ The Chinese University of Hong Kong, Tsimshatsui, Hong Kong \\ Julia Sze Wing Wong \\ Tung Wah College, Homantin, Hong Kong
}

\begin{abstract}
Medical-surgical nursing is a core subject in nursing education in which student nurses study diseases and relevant nursing interventions. However, student nurses consider it as one of the most difficult subjects because of the higher-order thinking skills required to master and connect the concepts. Therefore, this study introduces peer instruction (PI), together with information and communication technology (ICT), to the student nurses' educational plan. The purpose of this study is to evaluate the effectiveness of PI in promoting deep learning and motivating students in the field of medical-surgical nursing. Mixed research methods were used and results showed that students' understanding levels were significantly improved after peer discussion and that the majority of the students agreed that PI provided them with a positive learning experience, enhanced their motivation to learn, and promoted deep learning. To conclude, PI with ICT is effective on fostering deep learning and increasing students' motivations to pursue medical-surgical nursing.
\end{abstract}

Keywords: peer instruction (PI), nursing education, medical-surgical nursing, deep learning, motivation

\section{Background/Objectives and Goals}

As educators, we no longer transfer knowledge to students, but rather develop a meaningful learning environment to promote knowledge development, deep learning, and critical thinking by motivating students to be actively engaged in the learning process. Researchers have suggested that an effective teaching-learning process in higher education, rather than rely on traditional instruction alone, should actively involve students and teachers equally and prompt both parties to monitor learning outcomes throughout the learning process (Bastable, 2014; Gillespie \& Mcfetridge, 2006; Trigwell, 2010). Moreover, when devising teaching plans, teachers should incorporate elements that will help equip students with 21 st century skills, which will enable them to succeed in this ever-changing world, including creativity and innovation; critical thinking, problem solving, and decision making; improved learning capacities and metacognition; communication; collaboration; information literacy; information and communication technology literacy; citizenship; life and career planning; and personal and social responsibility (Binkley et al., 2012).

Offered as a series of 4-5 courses, medical-surgical nursing is a core subject in Hong Kong nursing education in which student nurses study diseases and relevant nursing interventions. Furthermore, the basic 
knowledge provided in the subject can help student nurses formulate nursing care plans to provide appropriate, effective, and holistic care to patients - a core competence of professional nurses for clinical practice and one required by the Nursing Council of Hong Kong (2012). However, student nurses consider medical-surgical nursing the most difficult subject because of the higher-order thinking skills required to connect the concepts together. In one local private nursing school where traditional didactic teaching is used as part of a Higher Diploma in Nursing programme, the failure rate in this subject is relatively higher than in other nursing subjects. Student nurses are passive receivers, sitting in the classroom every day for hours absorbing one-way information about medical-surgical nursing. This study aims to improve this learning environment by using the interactive learning approach of peer instruction (PI) in one of the medical-surgical nursing courses to motivate students and promote deep learning.

\section{Peer Instruction}

PI is a student-centered teaching method first developed by physics lecturer Eric Mazur. Mazur (1997) found that traditional and simple lucid lecturing was ineffective in student learning, because students on the receiving end of this teaching method failed to gain an adequate understanding of the information content of the lecture. Accordingly, Mazur employed PI to deepen students' understandings and enhance their application of knowledge by engaging them in the learning process (Mazur, 1997). Students are engaged in lectures through interactive activities that promote cognitive thinking and collaboration. Furthermore, PI has been widely used across different disciplines, such as physics, computer science, nursing, and medical education (Chase \& Okie, 2000; Brannagan et al., 2013; Szlachta, 2013).

\section{Deep Learning}

We live in the era of the knowledge economy, and the dominant mode of learning is shifting from traditional schooling, known as instructionism, to deep conceptual understanding (Sawyer, 2006). Sawyer (2006) suggested five essential elements for this new era of learning: deeper conceptual understanding, focusing on students' learning processes, creating a constructive learning environment, building on learners' existing knowledge, and reflecting on the state of that knowledge. This deep conceptual understanding approach benefits students, who can better retain knowledge and apply it in an authentic environment. Particularly, in the field of nursing, students are required to integrate their theoretical knowledge into clinical practice. Therefore, deep learning is crucial to their success and should be actively promoted in nursing education. According to Sawyer (2006), deep learning practice occurs when students are engaged in learning, demonstrates students' abilities to integrate knowledge, and reflects on students' understandings and their own process of learning. Biggs (1999) and Lublin (2003) asserted that teaching that involves students in active and independent learning tends to encourage a deep approach to a subject. One of the objectives of this paper is to determine whether deep learning occurs when PI is incorporated in lectures.

\section{Motivation}

According to Parlett (2012, p. 1), "Motivation influences students' behaviours in the classroom and determines the way students learn, how they perform, and the type of objectives they establish." To promote student learning, educators in the field of nursing must design learning environments in which students are actively engaged in the learning process (Bastable, 2014). It is particularly important to keep student nurses motivated in their learning. Nursing education researchers have found that students' motivations is the main 
factor affecting their learning (Mariette \& Bodil, 2010). If students are not motivated, they may have a poor attention span in class. Furthermore, they are usually unable to acquire deep learning and thus apply the knowledge in practice (Mariette \& Bodil, 2010), because motivation is the key to influencing students' learning behaviours and their engagements in learning. Therefore, effective pedagogy should be used to foster students' motivations, facilitate their learning, and enhance their learning outcomes. Achieving learning outcomes ensures the quality of the nursing students' knowledge and skills.

\section{Methods}

\section{Study Design}

Mixed research methods were used in this study. The following research questions guided this study:

1. Can PI promote deep learning among student nurses?

2. Can PI enhance student nurses' motivation?

3. What learning experiences do students encounter in lectures?

4. What teaching experiences are associated with using PI?

\section{Participants}

The participants were all second-year student nurses in a local private nursing school pursuing the Higher Diploma in Nursing programme in 2015.

\section{Quantitative Method}

This study was carried out in a six two-hour lectures about medical-surgical nursing of genitourinary system. The subject covered eight areas: assessments of the renal system, urinary tract infection, voiding dysfunction, genitourinary calculi and trauma, bladder disease, prostate disease, kidney disease, and renal failure. The lecturer used PI in teaching all of these eight areas.

First, the lecturer uploaded pre-lecture reading materials, such as articles, booklets, and videos, to Edmodo one week before the lecture. Edmodo is a social electronic platform that students and teacher can use to communicate and share information. The students were required to read all materials before the lecture. Immediately upon arriving for the lecture, students were required to complete a concept pre-test on their iPads in Edmodo. No discussion was allowed. The concept test was composed of eight multiple-choice questions (MCQs), the design of which was based on Bloom's taxonomy, a category of learning activities and behaviours, which reflects the level of thinking skills, ranging from lower- to higher- order: remembering, understanding, applying, analysing, evaluating, and creating (Krathwohl, 2002). Among the eight MCQs, four tested students' application of knowledge, two tested understanding of conceptual knowledge, and two tested analysis.

After the students completed the concept test, the instructor asked them to share their answers with classmates sitting nearby. The students were encouraged to explain their rationale for selecting their answers. If their answers differed from their peers', they had to present arguments to persuade one another. After a few minutes of discussion, the students completed the same concept test again as a post-test. Then, the instructor projected the distribution of students' pre- and post- test answers and initiated a class-wide discussion. The students were invited to share their answers and explain their rationales. Throughout the class-wide discussion, the instructor assessed the level of understanding and rectified misconceptions, if any. At the end of the lecture, the MCQs with explanations were posted on Edmodo for students' reference. The comparison of pre- and posttest scores was used to evaluate whether deep learning occurred among student nurses. 
At the end of the last lecture, the students were invited to complete a 14-item online satisfactory survey to evaluate their level of satisfaction with PI. The survey comprised 14 statements, including a measurement of the level of agreement using a five-point Likert scale ("1= Strongly disagree;" "2 = Disagree;" "3 = Neutral;" "4 = Agree;" and "5 = Strongly agree”). The statements were designed to assess students' learning experiences, motivation, and deep learning.

\section{Qualitative Method}

The lecturer used a reflective journal to record her teaching experiences after each lecture.

\section{Results}

\section{Concept Tests}

A total of 83 students (six males and 77 females) participated in this study. The data were analysed by using International Business Machine (IBM) Statistical Product and Service Solutionst (SPSS) for Windows version 23.0 (IBM Corp, Armonk, N.Y.). The McNemar's test was used to compare the correctness of each MCQ pre- and post- test. The $p$-values of all eight questions were below 0.05 , which means that the correctness of MCQs significantly improved in the post-test (see Table $1 \&$ Figure 1).

Table 1

Pre- and Post-Tests Results for Individual MCQs

\begin{tabular}{llll}
\hline MCQs & Pre-test (\%) & Post-test (\%) & $p$-value \\
\hline Q1 & 51.90 & 80.20 & 0.000 \\
Q2 & 25.90 & 87.70 & 0.000 \\
Q3 & 29.50 & 70.50 & 0.000 \\
Q4 & 80.00 & 92.50 & 0.006 \\
Q5 & 45.70 & 75.30 & 0.000 \\
Q6 & 58.40 & 84.40 & 0.000 \\
Q7 & 32.90 & 84.10 & 0.000 \\
Q8 & 46.30 & 81.70 & 0.000 \\
\hline
\end{tabular}

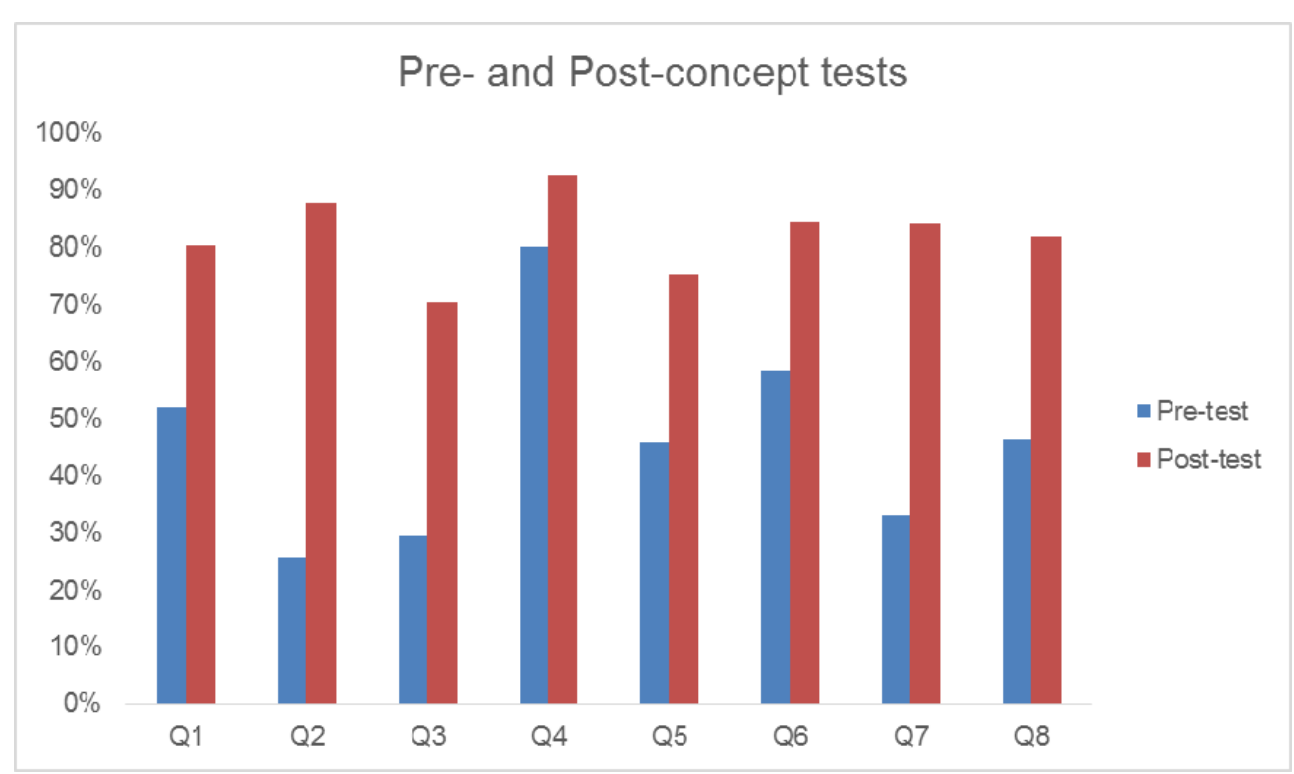

Figure 1. Pre- and post- tests results for individual MCQs. 


\section{Satisfaction Survey}

A satisfaction survey was conducted through an online platform with a $100 \%$ response rate. The overall results were positive and showed that the majority of students enjoyed the lectures and agreed that PI with information and communication technology (ICT) increased their motivation for learning and promoted deep learning.

\section{Learning Experience}

Over $85 \%$ of the students agreed that PI was more interactive and facilitated greater engagement compared to traditional learning methods. Thus, they preferred the integration of technologies and electronic resources in the lectures. In addition, they found the teacher's feedback by way of debriefing after completing each MCQ useful.

\section{Motivation}

Over $80 \%$ of the students agreed that this teaching method could increase their interest and motivation to learn.

\section{Deep Learning}

Over $85 \%$ of the students agreed that the concept test helped them to evaluate and enhance their understanding of the topics. In addition, $74 \%-81 \%$ of the students agreed that peer discussion aided their learning.

\section{Instructor's Reflective Journal}

The instructor concluded that students greatly enjoyed the PI lectures. The learning atmosphere was positive, as students were actively engaged in the peer discussion and participated well in the concept tests. Their attention and involvement in class were significantly improved compared with previous didactic lectures.

During the discussion among students, the instructor walked around the classroom and listened to their conversations, which allowed the instructor to assess their reasoning processes and address any common problems or misconceptions in the debriefing discussion. The students participated in constructive discussions, and some of them explained their rationale by referring to clinical experiences. The students demonstrated authentic learning and were able to build upon their existing knowledge. It was valuable to understand how the students explained their answers and connected their learning to authentic situations. In addition, it was also very useful to listen to how they explained wrong answers, as it provided deep reasoning when they considered the questions in contrast. The discussion showed that students' conception of learning was deepened through defending their answers, analysing the questions from different perspectives, articulating their understanding and presenting ideas in their own words.

After the students completed the post-test, the instructor initiated a class-wide discussion. Some of the students were invited to present their answers and explain their reasoning. This tactic aimed to test their understanding and logical thinking, and encouraging further learning. The students then provided a rationale for their answers. The students paid close attention to these arguments and examined them by themselves. They were excited when they learned that they had the right answers and explanation. The learning atmosphere was definitely improved as compared with traditional didactic teaching. Given the students' excitement during the lecture, PI transformed the classroom from a passive and boring learning environment to an interactive and fruitful one. The students appreciated the materials posted on the e-learning platform after the lectures, which provided opportunities for further learning. 


\section{Discussions}

PI was chosen over other methods for this study, because it is an interactive approach that can optimize students' learning experiences and enhance knowledge acquisition. Students are responsible for their own learning through active participation and are empowered with autonomy (Benner, Sutphen, Leonard, \& Day, 2010). Thus, PI provides opportunities for both students and teachers to be actively engaged in the learning process (Gillespie \& Mcfetridge, 2006). Furthermore, PI can be incorporated with ICT, which can further motivate 21 st century students while promoting deep learning.

The results of the concept test showed significant improvements in selecting the correct answer after peer discussion. Students' improvements in the concept test demonstrated that deep learning occurred after peer discussion, as the questions were designed based on Bloom's taxonomy. The students were able to achieve higher-order thinking through reasoning and analysis during peer discussion. The study results concurred with previous findings, which stated that PI could foster deep understanding (Simon \& Cutts, 2012). Mazur (1997) explained that an increase in correctness reflected a dramatic improvement in students' understanding levels when they could explain their reasoning and teach their peers.

The results of the satisfaction survey revealed that the students responded positively to the use of PI and were satisfied with this interactive teaching and learning method. PI can effectively increase students' engagements in the learning process. The design of the learning environment, featuring PI and technology, successfully optimized the student learning experience. The electronic learning platform Edmodo, in conjunction with the iPads, provided students with access to multimedia learning materials that maximized their knowledge acquisition and construction. These tools also provided students with autonomy in their studying and empowered their learning. Groenke and Paulus (2007) described Edmodo as a collaborative social learning platform that can disrupt traditional teacher-centred methods. In this study, students evolved from passive receivers to active participants in the learning process and became the focal point of learning. PI is effective on enhancing student engagement in the learning process and improving their behaviour, emotions, and cognitive engagement during learning activities, all of which leads to higher learning outcomes (Reeve \& Tseng, 2011). Furthermore, adopting this interactive approach enhanced students' motivations and learning experiences.

The results of the concept tests, along with the subjective experiences of the students and the instructor, provide a comprehensive picture of the impact of PI in different environments. These findings reflected many similar studies from around the world. The pre-lecture work enables students to practice self-regulated learning and improve their reading to learn techniques. Reading to learn is a learning skill for developing cognitive thinking, which enables students to process the content of reading materials (Maclellan, 1997). After students acquire the knowledge and general understanding from the pre-lecture reading materials, they articulate their understanding through peer discussion. In these conversations, students are actively engaged in the thinking process, because they have to explain their answers to their classmates with supporting rationales. In other words, knowledge is actively constructed rather than passively received by students. They have to put their thoughts into words, and discussions enable students to build upon their existing knowledge in learning something new. The concept test promotes self-efficacy among students, because it enables them to assess their own learning, and the learning process guides their own educational experience (Szlachta, 2013). It further promotes metacognition as students gain the ability to assess and monitor their own cognitive process (Gok, 
2012). When students engage in the discussion, they have to convince one another and analyse the question from different dimensions. The conversation between peers constructively uses argument as a tool for learning. Furthermore, PI nurtures a collaborative learning environment that can enhance students' motivations and interests in learning. It enables the instructor to walk around and listen to the discussion. PI provides a good opportunity for teachers to assess the level of understanding and identify common problems or misconceptions among students (Simon \& Cutts, 2012).

The class-wide discussion enables instructors to perceive how students analyse the questions, as well as their ways of thinking and understanding of the content. Students articulate their understanding by providing explanations, which fosters deep learning.

\section{Limitation}

Although the students performed well in PI and provided positive feedback, we have to address some limitations and make improvements for future teaching practices. The concept test's level of difficulty should be considered. Crouch and Mazur (2001) suggested that the difficulty of concept tests should be moderate, with the ideal correct rate between $35 \%$ and $70 \%$ prior to the discussion. Less than $35 \%$ would imply that the questions may be too difficult or ambiguous for students, while higher than $70 \%$ would imply that the questions are too easy. Both conditions can limit fruitful peer discussion. In this study, three questions received less than $35 \%$ correct responses and one question was answered correctly by more than $70 \%$ of students in the pre-test. Therefore, the design of questions should be improved in terms of their difficulty.

\section{Conclusion}

This study showed that PI with ICT seems effective on fostering deep learning and increasing students' motivations to pursue medical-surgical nursing. The use of PI in teaching medical-surgical nursing successfully transforms the students from passive to active learners during lectures. Students' performance in the concept tests showed improvements in how they acquired knowledge and indicated that they deepened their learning. Fruitful peer discussion also demonstrated that deep learning occurred among students as they articulated their understanding and used their knowledge to explain their rationales while applying their knowledge in authentic situations. The class-wide discussion under the lecturer's guidance helped to integrate knowledge and rectify some misconceptions. The students were satisfied with the PI pedagogy and demonstrated positive attitudes toward it. However, the sample size of this study is relatively small, the potential of PI needs to be explored further with more samples in this context.

\section{References}

Bastable, S. B. (2014). Nurse as educator: Principles of teaching and learning for nursing practice (4th ed.). Burlington, M.A.: Jones \& Bartlett Learning.

Benner, P., Sutphen, M., Leonard, V., \& Day, L. (2010). Educating nurses: A call for radical transformation. San Francisco, C.A.: Jossey-Bass.

Binkley, M., Erstad, O., Herman, J., Raizen, S., Ripley, M., Miller-Ricci, M., \& Rumble, M. (2012). Defining twenty-first century skills. In P. Griffin et al. (Eds.), Assessment and teaching of 21st century skills. Dordrecht: Springer Science + Business Media B.V..

Biggs, J. (1999). Teaching for quality learning at university. Buckingham: Society for Research into Higher Education and Open University Press.

Brannagan, K. B., Dellinger, A., Thomas, J., Mitchell, D., Lewis-Trabeaux, S., \& Dupre, S. (2013). Impact of peer teaching on nursing students: Perceptions of learning environment, self-efficacy, and knowledge. Nurse Education Today, 33(11), 1440-1447. 
Chase, J. D., \& Okie, E. G. (2000). Combining cooperative learning and peer instruction in introductory computer science. $A C M$ Special Interest Group on Computer Science Education (SIGCSE) Bulletin, 32(1), 372-376.

Crouch, C. H., \& Mazur, E. (2001). Peer instruction: Ten years of experience and results. American Journal of Physics, 69(9), 970-977.

Gillespie, M., \& Mcfetridge, B. (2006). Nursing education: The role of nurse teacher. Journal of Clinical Nursing, 15(5), 639-644.

Gok, T. (2012). The effects of peer instruction on students' conceptual learning and motivation. In Asia-Pacific Forum on Science Learning and Teaching, 13(1). Retrieved from http://www.ied.edu.hk/apfslt/download/v13_issue1_files/gok.pdf

Groenke, S. L., \& Paulus, T. (2007). The role of teacher questioning in promoting dialogic literary inquiry in computer-mediated communication. Journal of Research on Technology in Education, 40(2), 141-164.

Krathwohl, D. R. (2002). A revision of Bloom's taxonomy. Theory into Practice, 41(4), 212-225.

Lublin, J. (2003). Deep, surface and strategic approaches to learning. Retrieved from http://www2.warwick.ac.uk/services/ldc/ development/pga/introtandl/resources/2a_deep_surfacestrategic_approaches_to_learning.pdf

Maclellan, E. (1997). Reading to learn. Studies in Higher Education, 22(3), 277-288.

Mariette, B., \& Bodil, O. (2010). The nursing and medical students motivation to attain knowledge. Nurse Education Today, 30(2), 150-156.

Mazur, E. (1997). Peer instruction: Getting students to think in class. AIP Conference Proceedings, 399(1), 981-988.

Nursing Council of Hong Kong. (2012). Core-competencies for registered nurses (General). Retrieved from http://www.nchk.org.hk/filemanager/en/pdf/core_comp_english.pdf

Parlett, D. K. (2012). A comparison of associate and bachelor degree nursing students' motivation (Unpublished doctoral dissertation, Walden University, USA).

Reeve, J., \& Tseng, C. M. (2011). Agency as a fourth aspect of students' engagement during learning activities. Contemporary Educational Psychology, 36(4), 257-267.

Sawyer, R. K. (2006). The new science of learning. In R. K. E. Sawyer (Ed.), The Cambridge handbook of learning sciences (pp. 1-16). New York, N.Y.: Cambridge University Press.

Simon, B., \& Cutts, Q. (2012). Peer instruction: A teaching method to foster deep understanding. Communications of the ACM, $55(2), 27-29$.

Szlachta, J. (2013). Peer instruction of first-year nurse anesthetist students: A pilot study of a strategy to use limited faculty resources and promote learning. The Journal of Nursing Education, 52(6), 355-359.

Trigwell, K. (2010). Promoting effective student learning in higher education. In P. Peterson, E. Baker, \& B. McGaw (Eds.), International Encyclopedia of Education (Vol. 4, pp. 461-466). Oxford: Elsevier. 